\title{
Transcortical Endoscopic Surgery for Intraventricular Lesions
}

\author{
Myung-Hyun Kim, M.D., Ph.D. \\ Department of Neurosurgery, Ewha Womans University Mokdong Hospital, Seoul, Korea
}

To review recent advances in endoscopic techniques for treating intraventricular lesions via transcortical passage. Articles in PubMed published since 2000 were searched using the keywords 'endoscopy,' 'endoscopic,' and 'neuroendoscopic.' Of these articles, those describing intraventricular lesions were reviewed. Suprasellar arachnoid cysts (SACs) can be treated with ventriculo-cystostomy (VC) or ventriculo-cysto-cisternostomy (VCC). VCC showed better results compared to VC. Procedure type, fenestration size, stent placement, and aqueductal patency may affect SAC prognosis. Colloid cysts can be managed using a transforaminal approach (TA) or a transforaminal-transchoroidal approach (TTA). However, TTA may result in better exposure compared to TA. Intraventricular cysticercosis can be cured with an endoscopic procedure alone, but if pericystic inflammation and/or ependymal reaction are seen, third ventriculostomy may be recommended. Tumor biopsies have yielded successful diagnosis rates of up to $100 \%$, but tumor location, total specimen size, endoscope type, and vigorous coagulation on the tumor surface may affect diagnostic accuracy. An ideal indication for tumor excision is a small tumor with friable consistency and little vascularity. Tumor size, composition, and vascularity may influence a complete resection. SACs and intraventricular cysticercosis can be treated successfully using endoscopic procedures. Endoscopic procedures may represent an alternative to surgical options for colloid cyst removal. Solid tumors can be safely biopsied using endoscopic techniques, but endoscopy for tumor resection still results in considerable challenges.

Key Words : Endoscopy · Arachnoid cysts · Cysticercosis · Colloid cyst · Intraventricular tumor.

\section{INTRODUCTION}

Endoscopic surgery in neurosurgery began with the use of a transcortical intraventricular procedure, including choroid plexus coagulation or endoscopic third ventriculostomy (ETV), to control hydrocephalus ${ }^{12}$. The ventricular space may have enough room for endoscopic surgery, and the ventricular cerebrospinal fluid (CSF) serves as a good natural medium for image transmission. The introduction of new instruments, including rod lens Hopkins optics, high-resolution cameras, and frameless stereotaxy, has led to a tremendous increase in the number of neuroendoscopic procedures performed since the early 1990s. Recently, the application of endoscopic surgery has extended into various diseases relevant to the neurosurgical field, including transcortical intraventricular lesions, such as arachnoid cyst intraventricular extensions ${ }^{17,40)}$, colloid cysts $^{22,26,54)}$, and intraventricular cysticercosis ${ }^{24,53)}$. New applications include biopsies ${ }^{13,39,44,49,52)}$ and intraventricular brain tumor removal ${ }^{6,50)}$. In this article, we will discuss the management of all transcortical intraventricular lesions, with the exceptions of ETV and complicated hydrocephalus.

- Received : January 2, 2017 •Revised : March 25, 2017 •Accepted : April 24, 2017

- Address for reprints : Myung-Hyun Kim, M.D., Ph.D.

Department of Neurosurgery, Ewha Womans University Mokdong Hospital, 1071 Anyangcheon-ro, Yangcheon-gu, Seoul 07985, Korea Tel : +82-2-2650-5088, Fax : +82-2-265-5088, E-mail : kimmh@ewha.ac.kr

This is an Open Access article distributed under the terms of the Creative Commons Attribution Non-Commercial License (http://creativecommons.org/licenses/by-nc/4.0) which permits unrestricted non-commercial use, distribution, and reproduction in any medium, provided the original work is properly cited. 


\section{ARACHNOID CYSTS}

Arachnoid cysts (ACs) are usually incidental findings, but can result in significant neurological symptoms that require surgery. ACs can arise from incomplete separation of the endomeninx during embryogenesis. The mechanism of cyst expansion is still unknown. Possible explanations are the secretion of fluid from the cyst wall, arterial pulsations through a one-way valve, and an osmotic gradient-induced accumula$\operatorname{tion}^{42)}$. The definitive surgical method to manage asymptomatic AC is still controversial. Open surgery with cyst excision $^{35)}$, cyst fenestration ${ }^{43)}$, stereotactic aspiration ${ }^{25)}$, and cystoperitoneal shunting ${ }^{8}$ have all been proposed. Recently, endoscopic fenestration procedures have been adopted as a less invasive, and more effective, treatment for $\mathrm{AC}^{16,17,21,38,40)}$.

Most surgeons agree that patients with neurological symptoms, which can include increased intracranial pressure, should be treated. In addition, extremely large asymptomatic cysts are often considered candidates for therapy to prevent developmental delays in children. Symptomatic ACs adjacent to a normal CSF-containing space are particularly good candidates for endoscopic surgery ${ }^{16,17,21,38,40)}$. The goal of endoscopic techniques is to produce equal pressure gradients through a cyst opening using the natural exchange of $\mathrm{CSF}^{38}$. Planning the trajectory is often a very important aspect of the procedure. Entry sites that can provide a direct route to the cyst and minimize any torque on the cortical or intraventricular neurovascular tissue are preferred ${ }^{21)}$. Therefore, it is possible to choose an optimal entry point and trajectory using a frameless stereotaxic system that minimizes risk of neurovascular injury $^{16,21)}$. However, the surgical team must be aware that the brain can shift during these procedures due to CSF drainage and positioning ${ }^{15}$. An intraoperative imaging device that can show procedure progress, such as an endoscopic ultrasound probe, might be a better option in the near future for these surgeries ${ }^{16)}$. In addition, many factors affect outcome, including the size of the fenestration, insertion of a catheter or stent ${ }^{2,51)}$, the presence of hydrocephalus, and occurrence of intraoperative bleeding ${ }^{16,21,38)}$.

Of the various possible intracranial arachnoid cyst locations, we only included suprasellar ACs in this study because they showed the most favorable surgical outcomes from endoscopy. In addition, endoscopic treatment could become the standard trancortical intraventricular technique for this condition.

\section{Suprasellar arachnoid cysts}

Suprasellar ACs (SACs) account for about 5\% to $12.5 \%$ of all ACs ${ }^{17,55)}$. SACs arise from an anomaly of the Liliequist membrane, either a diverticulum or splitting, and CSF accumulation within the cavity. Some researchers suggest that a basilar artery piercing the prepontine arachnoid membrane results in a slit valve mechanism and contributes to the expansion of $\mathrm{AC}^{3,18,45)}$. SACs can result in obstructive hydrocephalus by compressing the foramen of Monro or cerebral aqueduct. In addition, various symptoms can result from large cysts in this region, including visual impairments, endocrinopathy, head bobbing, developmental delay, gait ataxia, and seizures $^{17,21,40)}$.

Planning the precise entry site is crucial for endoscopic procedures. A specific trajectory is selected so that the endoscope will facilitate fenestration at both the apical and basal cyst membranes, without causing any torque affecting the vital neurovascular structures rostral or caudal to the cyst. A frontal burr hole is placed on the coronal suture $2-3 \mathrm{~cm}$ off the midline. After puncture of the lateral ventricle with a peelaway catheter, the endoscope is advanced. Ventriculo-cystostomy (VC) or ventriculo-cysto-cisternostomy (VCC) should be used on an individual case basis. During VC procedures, cysts can be difficult to enter due to membrane thickness. Since the upper membrane may bounce away with a blunt balloon, a sharp instrument like an electrode or scissors is often required. After perforation of the upper membrane, the opening can be enlarged and dilated using the balloon, electrocoagulation, or scissors. Through this opening, the internal wall of the cyst is followed along the clivus. The lower membrane can also be quite tough, but is usually thinner. If there is a risk of injuring the basilar artery or perforating vessels, the cysto-cisternostomy may be abandoned.

Many prognostic factors exist, including procedure type (VC or VCC), fenestration size, valve-like mechanism destruction, placement of a catheter or stent, and patency of the aqueduct $^{17)}$. A large opening $(1-1.5 \mathrm{~cm})$ and shrinkage of the upper cyst wall have been recommended ${ }^{17,40)}$. The aqueduct may be closed later by the redundant cyst wall or mesencephalic compression of the residual cyst ${ }^{48,55)}$. The choice between $\mathrm{VC}$ and VCC for endoscopic management of SAC is controversial. Some studies demonstrated excellent outcomes after VC, with a success rate ranging from $93.8 \%$ to $100 \%{ }^{48}$. These studies advocated several techniques, including large fenestrations 
( $>10 \mathrm{~mm}$ ), a septum pellucidotomy in cases of asymmetrical lateral ventricles, and shrinkage coagulation of the cyst wall. Ogiwara et al. ${ }^{40)}$ proposed that preoperative cisternography may be useful for selecting patients who are suitable for VC. VCC may be suitable for patients not or slightly communicating with the basal cisterns. Maher et al. ${ }^{31)}$ found that $\mathrm{VC}$ failed in $16 \%(7 / 44)$ of their patients and required a second procedure, whereas VCC only failed in $8 \%$ (7/86). The reoperation rate was significantly higher following VC compared to VCC. In addition, El-Ghandour ${ }^{17)}$ performed $11 \mathrm{VC}$ and $14 \mathrm{VCC}$ procedures on $25 \mathrm{SAC}$ cases, and found that cyst size improvement occurred in $81.8 \%$ after VC compared with $100 \%$ after VCC. Hydrocephalus improvement was found in $63.6 \%$ and $85.7 \%$ of patients after VC and VCC, respectively. Recurrence was observed in $27.3 \%$ (1/11) of VC cases, whereas no recurrence $(0 \%)$ was observed after VCC. Rangel-Castilla et al. ${ }^{41)}$ reported that aqueductal obstruction may be associated with AC, which could result in VC failure. Therefore, it is better to inspect the patency of the aqueduct during the operation. In the case of aqueductal occlusion, VCC would be the better treatment. These endoscopic procedures can also be used to treat various juxta-ventricular cysts, including intrasellar or fourth ventricular ACs.

\section{COLLOID CYSTS}

Colloid cysts are benign unilocular intraventricular tumors that most frequently arise from the roof of the third ventricle. The proximal location of the cyst relative to the foramen of Monro may lead to either chronic or acute obstruction of CSF outflow. Although most patients present with symptoms related to hydrocephalus, sudden death can also occur.

There are various methods to treat colloid cysts surgically, including transcortical and transcallosal craniotomy ${ }^{5,14,47)}$, CSF shunting, stereotaxic cyst aspiration ${ }^{1)}$, and endoscopic removal $^{28)}$. Open surgery is considered the standard approach, but endoscopic techniques have recently been recognized as a viable and safe alternative. The main disadvantages of endoscopic techniques are the relatively steep learning curve, difficulties in bimanual procedures, and frequent obscuration of the lens ${ }^{46}$.

Endoscopic procedures to manage colloid cysts include a transforaminal approach (TA) and a combined transforami- nal-transchoroidal approach (TTA) with a single or double rigid endoscope at 0 or 30 degrees.

In TA, a single burr hole is placed $8 \mathrm{~cm}$ posterior to the nasion and $7 \mathrm{~cm}$ lateral to the midline. Since this entry point is not the usual location for ventricular access, frameless stereotaxy is needed to plan a safe trajectory and avoid the caudate head $^{22,54)}$. Wait et al. ${ }^{54)}$ demonstrated 15 successful cyst removals in cases without ventriculomegaly using a rigid, $6 \mathrm{~mm}$, 30 -degree endoscope under the usual irrigation to prevent ventricular collapse. Care must be taken during this approach, to avoid or minimize injury to the fornix and bleeding from the choroid plexus and venous structures ${ }^{22,26,54)}$. Iacoangeli et al. $^{26)}$ proposed the TTA approach. TA may not allow for adequate control of the cyst, especially when it is located in the posterior third ventricle, resulting in residual and recurrent cysts after endoscopic removal ${ }^{29)}$. Using a transchoroidal route, the third ventricular roof can be totally explored, the colloid cyst completely visualized, and intracapsular debulking and subsequent removal of the capsule facilitated ${ }^{22}$. With the patient in a supine position, with the head placed neutrally, a burr hole is made at the typical coronal point. After ventricular puncture, the endoscope is introduced into the lateral ventricle. The usual anatomical landmarks, such as the thalamostriate vein, septal vein, choroid plexus, and foramen of Monro, can be recognized in addition to the cyst. First, via the transforaminal route, the cyst is opened and decompressed with either an aspiration tool or grasping forceps based on the viscosity of the cyst contents. The capsule is then resected in a piecemeal fashion. The choroidal fissure is opened medial to the choroid plexus through the tenia fornicis. Two layers of the tela choroidea are opened, and the posterior part of the cyst and its attachments are completely exposed. After careful dissection, the capsule can be removed through the transforaminal or transchoroidal route (Fig. 1) ${ }^{26)}$.

The rate of recurrence ranges from $0 \%$ to $11.47 \%$. The average rate of recurrence is higher in cases with partial resection $(6.87 \%)$ compared to total resection $(0.71 \%)^{4,33,34)}$.

\section{NEUROCYSTICERCOSIS}

Neurocysticercosis is caused by Taenia solium larvae, which is the most frequent helminthic infestation of the central nervous system. It presents as intraparenchymal-, cisternal-, or 

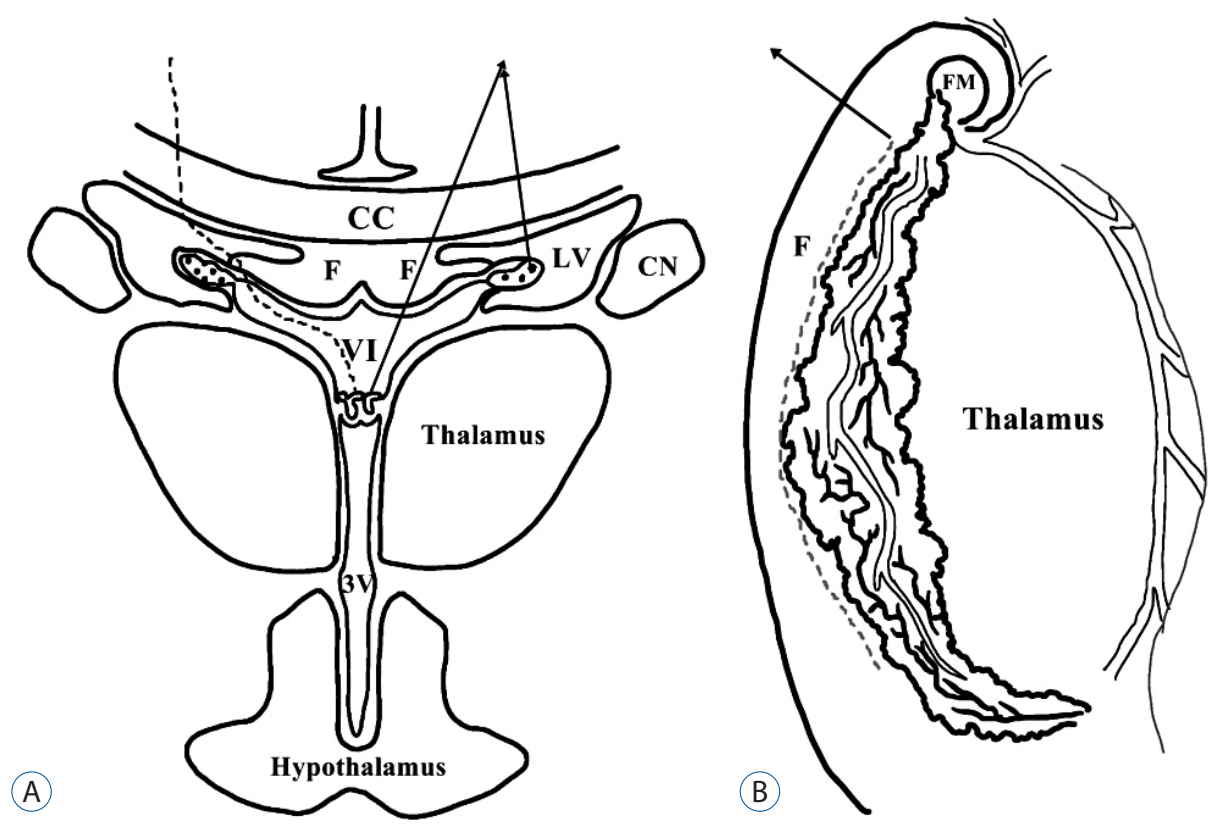

Fig. 1. Schematic drawing of the endoscopic transchoroidal approach. A : Coronal view: Under the endoscopic view in the lateral ventricle, after the careful dissection along the medial aspect of the choroid plexus, the roof of 3rd ventricle is exposed through the velum interpositum (dotted line). Arrows : choroid plexus of lateral and third ventricle, dotted line; dissection plane of transchoroidal approach. B : Endoscopic view of the right lateral ventricle: Between the fornix and choroid plexus, the velum interpositum can be exposed safely. Arrowed dotted line : dissection plane of transchoroidal approach. CC : corpus callosum, CN : caudate nucleus, LV : lateral ventricle, F : fornix, VI : velum interpositum, $3 \mathrm{~V}$ : third ventricle, F : right fornix, FM : foramen Monro.

intraventricular-type within the intracranial space ${ }^{10,56)}$. Often, the cisternal cyst can move into the ventricles, especially in the presence of a shunt ${ }^{24)}$. Cases with intraventricular involvement are often more difficult to manage due to CSF pathway obstruction, as well as ependymal and arachnoidal inflammation; these cases account for 7 to $33 \%$ of all neurocysticercosis cases ${ }^{11}$. These mobile, deformable cysts can cause intermittent CSF obstruction with episodic increases in intracranial pressure due to a ball and valve mechanism (Brun's syndrome), causing fatal, acute obstructive hydrocephalus ${ }^{53)}$.

There are three options to manage intraventricular cysticercosis: anthelmintic medical therapy, CSF diversion, and surgery to remove the cyst. In cases with symptomatic hydrocephalus, surgery is the only option. During surgery, the goals are to treat the hydrocephalus, avoid shunting, and remove cysts obstructing CSF pathways and all intraventricular cysts (to prevent cyst-induced inflammation). If needed, ETV and/ or a septum pellucidotomy can be performed simultaneously. Cysts located in the lateral or third ventricles can be removed via the usual coronal burr holes using a rigid or flexible endoscope $^{53}$, but transaqueductal or transforaminal manipulation is needed for cysts in the fourth ventricle ${ }^{24)}$.

Ventriculitis is not usually observed, despite cyst rupture $^{24,53)}$. Some researchers described surgical failures after cyst removal, probably caused by an ependymal reaction that in turn causes delayed obstruction of CSF pathways and increased intracranial pressure ${ }^{7,9,24)}$. If pericystic inflammation and/or ependymal reaction are demonstrated during preoperative magnetic resonance (MR) enhancement, simultaneous ETV is recommended ${ }^{24)}$.

\section{TUMOR BIOPSY}

Endoscopic biopsy of intraventricular tumors was first described by Fukushima in $1978^{19)}$. This method offers direct vision of, and approach to, deep-seated tumors located adjacent to the ventricles, as well as simultaneous management of the combined obstructive hydrocephalus through $\mathrm{ETV}^{13)}$. Endoscopic techniques are also beneficial for evaluating potential metastatic tumors. When inspecting CSF, avoiding vascular structures, such as the choroid plexus, and decompressing the 
cystic part of tumor, are essential ${ }^{49)}$.

Patients are placed in a supine position with the head elevated to 30 degrees above the horizontal plane to minimize CSF egress. To avoid undue torque, entry sites that offer the most direct route to the target are chosen. Ventricular cannulation is accomplished using stereotactic guidance with a ventricular catheter. CSF is collected for biochemical and cytological study before any tissue manipulation.

In cases with normal-sized ventricles (fronto-occipital ratio less than 38\%), ventricular insufflation with lactated Ringer's solution $(10 \mathrm{~mL})$ is performed with care to avoid bradycardia caused by an increase in intracranial pressure ${ }^{49)}$. If needed, ETV is performed prior to the biopsy procedure to prevent abandonment of successful procedures due to bleeding ${ }^{13,44,49,52)}$. Cupped biopsy forceps are used without any preceding coagulation when possible. Typically, a small amount of venous bleeding occurs during diagnostic sampling and is usually controlled with directed irrigation.

Various endoscopic techniques combining ETV and tumor biopsy have been demonstrated, including procedures with 1) a rigid endoscope through a standard coronal burr hole $\left.{ }^{37)}, 2\right)$ two rigid endoscopes through two separate burr holes (one standard coronal burr and one more anteriorly placed for a biopsy $)^{27)}$, 3) a flexible endoscope through a single burr hole ${ }^{37)}$, and 4) combined rigid and flexible endoscopes (Fig. 2) ${ }^{13,37,44)}$.

In procedure 1), unwanted pressure on the fornix during ETV and the foramen of Monro during biopsy can occur. Therefore, this procedure is only applicable when the tumor is located anteriorly in the third ventricle or is larger than $2 \mathrm{~cm}$. In procedure 2), the need for two burr holes and two transcortical routes are the major problems. Flexible endoscopes can reach distant locations with only one entry, even for aqueductal and fourth ventricular tumors. However, these endoscopes only provide limited visual quality and have a smaller working channel. The combined use of a flexible and a rigid endoscope may be helpful, particularly in complicated cases. Endoscopic tumor biopsies typically yield a definitive diagnosis rate between $43 \%$ and $100 \%$, whereas ETV has a success rate of between $64 \%$ and $100 \%{ }^{13,36,39,44,49)}$.

The rate of definitive diagnosis is significantly improved using a rigid endoscope (76\%) compared to a flexible endoscope $(43 \%)^{13)}$. The factors affecting successful biopsy are tumor location, specimen size, and vigorous coagulation of the tumor surface. In cases with a smaller specimen, the entire obtained specimen should be preserved for permanent section without freezing ${ }^{13,49)}$. Husain et al. ${ }^{23)}$ showed that combining cytological evaluation with conventional histological approaches improved the diagnostic yield from $77.4 \%$ to 93.5\%. In addition, Tamura et al. ${ }^{52)}$ demonstrated the use of a 5-aminolevulinic acid-induced protoporphyrin IX fluorescence imaging system to visualize a third ventricular malignant glioma prior to biopsy.

CSF tumor markers can often be helpful in the diagnosis of pineal and suprasellar tumors ${ }^{13)}$. Significant complications occur in 0 to $18 \%$ of patients ${ }^{2,13,39,44,49)}$, which can include bleeding (10\%), forniceal contusion, massa intermedia dis-
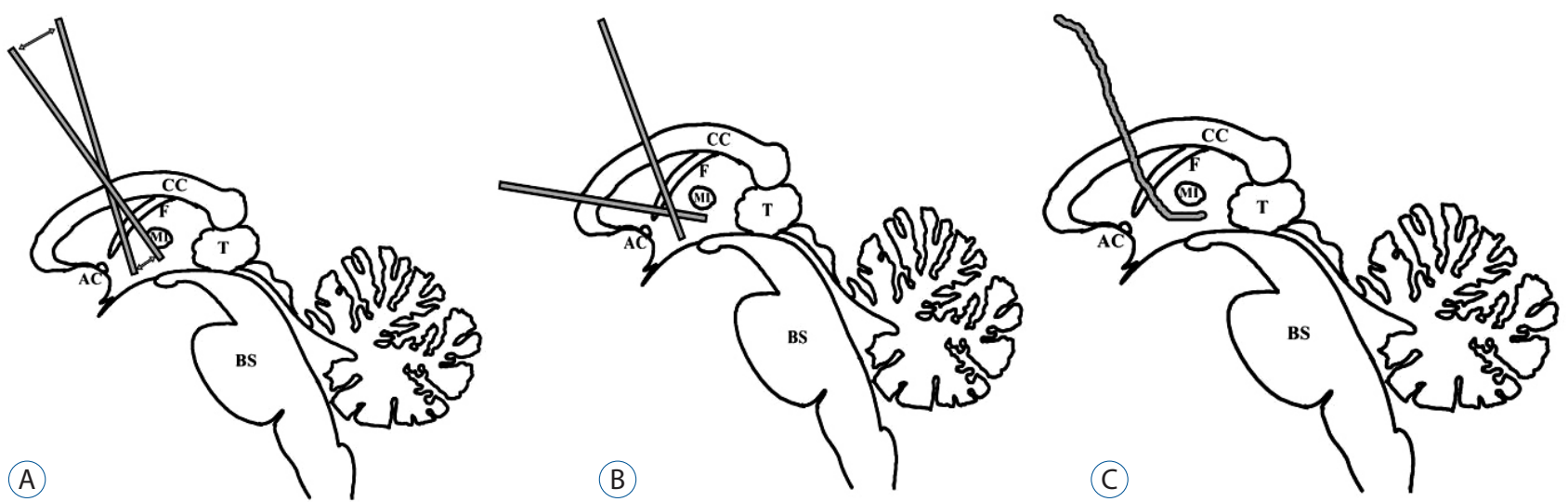

Fig. 2. Various endoscopic techniques combining an ETV and tumor biopsy. A : procedure with a rigid endoscope through a standard coronal burr hole. B : procedure with 2 rigid endoscopes through 2 separate burr holes (one standard coronal burr and one more anteriorly placed for a biopsy). C : procedure with a flexible endoscope through single burr hole. AC : anterior commissure, BS : brain stem, CC : corpus callosum, F : fornix, MI : massa intermedia, T : tumor, ETV : endoscopic third ventriculostomy. 
ruption (3.1\%), and vegetative state (3.1\%). The incidence of significant hemorrhage is between $2.3 \%$ and $3.5 \% \%^{13,30,39,44,49)}$. To prevent hemorrhagic complications, precisely visualizing the biopsy site and obtaining meticulous hemostasis after the biopsy procedure are essential ${ }^{13)}$. Manwaring et al. ${ }^{32)}$ proposed a small-chamber irrigation technique as a simple maneuver for managing intraoperative hemorrhage during endoscopic intraventricular surgery.

\section{TUMOR RESECTION}

Tumors that originate within the ventricular system represent a major neurosurgical challenge. These tumors are commonly managed by microsurgery via transcallosal or transventricular routes, which offer reduced mortality and morbidity. In defined cases, an endoscopic approach is superior to microsurgery ${ }^{6,50)}$. Approaches that use a burr hole are less invasive, and brain retraction can largely be avoided when using endoscopic techniques. It is also possible to restore obstructed CSF pathways by performing ventriculostomy, septotomy, and stent implantations. An ideal indication for endoscopic surgery is a small tumor with relatively friable consistency, and little of the vascularity that causes ventricle enlargement.

For convenience, the endoscopic resection of intraventricular tumors is performed using a rigid endoscope rather than a flexible one. However, this procedure has several limitations, including visual constraints, limitations in the size of the lesion that can be removed, the use only of two working channels, and possible conversion to open craniotomy ${ }^{20)}$. Often, these technical limitations and the limited use of non-traditional instruments may be a critical handicap when complications accur ${ }^{57)}$. The size, composition, and vascularity of a tumor may influence the possibility of a complete endoscopic resection.

To improve precision, the use of a frameless, stereotaxic, ultrasound-guided navigation system during endoscopic procedures may be helpful ${ }^{1,58)}$. Several researchers have introduced new instruments to manage intraventricular tumors, since traditional instruments are limited. Souweidane and Luther ${ }^{50)}$ described successful tumor resection with an endotracheal suction catheter through an endoscopic procedure, using pulse aspiration technique and alternating with blunt dissec- tion. Carr et al. ${ }^{6)}$ demonstrated a case of successful removal of an intraventricular primitive neuroectodermal tumor with a urological basket retriever using a usual endoscopic approach after cytoreduction with adjuvant chemotherapy and stem cell support.

\section{CONCLUSION}

Like other surgeries, endoscopic techniques require a lengthy learning process, during which the surgeon accumulates invaluable experience. Appropriate patient selection, preoperative planning of endoscope trajectory, the use of frameless navigation, and advances in endoscopic instruments and techniques make these procedures relatively safe and generally result in excellent outcomes. Transcortical intraventricular endoscopic procedures can be applied to various pathologies, but results vary. SACs and intraventricular cysticercosis are the best candidates for endoscopic surgery. In addition, endoscopic procedures may be an alternative surgical option for colloid cysts. At present, solid intraventricular tumors can be safely biopsied through endoscopy, but total resection using endoscopic techniques is still challenging. To overcome these issues, more advanced techniques and instruments are needed.

\section{References}

1. Auer LM : Intraoperative ultrasound as guide for neurosurgical endoscopic procedures. Acta Radiol Suppl 369 : 164-166, 1986

2. Berlis A, Vesper J, Ostertag $C:$ Stent placement for intracranial cysts by combined stereotactic/endoscopic surgery. Neurosurgery 59(4 Suppl 2) : ONS474-ONS479; discussion ONS479-ONS480, 2006

3. Binitie 0 , Williams B, Case CP : A suprasellar subarachnoid pouch; aetiological considerations. J Neurol Neurosurg Psychiatry 47 : 10661074, 1984

4. Boogaarts HD, Decq P, Grotenhuis JA, Le Guérinel C, Nseir R, Jarraya B, et al. : Long-term results of the neuroendoscopic management of colloid cysts of the third ventricle: a series of 90 cases. Neurosurgery 68 : 179-187, 2011

5. Bosch DA, Rähn T, Backlund EO : Treatment of colloid cysts of the third ventricle by stereotactic aspiration. Surg Neurol 9 : 15-18, 1978

6. Carr K, Zuckerman SL, Tomycz L, Pearson MM : Endoscopic removal of an intraventricular primitive neuroectodermal tumor: retrieval of a freefloating fragment using a urological basket retriever. J Neurosurg 
Pediatr 12 : 25-29, 2013

7. Chawla S, Gupta RK, Husain N, Garg M, Kumar R, Kumar S : Prediction of viability of porcine neurocysticercosis with proton magnetic resonance spectroscopy: correlation with histopathology. Life Sci 74 : 1081-1092, 2004.

8. Ciricillo SF, Cogen PH, Harsh GR, Edwards MS : Intracranial arachnoid cysts in children. A comparison of the effects of fenestration and shunting. J Neurosurg $74: 230-235,1991$

9. Citow JS, Johnson JP, McBridge DQ, Ammirati $M$ : Imaging features and surgery-related outcomes in intraventricular neurocysticercosis. Neurosurg Focus 12 : e6, 2002

10. Cuetter AC, Andrews RJ : Intraventricular neurocysticercosis: 18 consecutive patients and review of the literature. Neurosurg Focus 12 : e5, 2002

11. Cuetter AC, Andrews RJ : Intraventricular neurocysticercosis in Singh G, Prabhakar S (eds): Taenia Solium Cysticercosis. Oxford : CABI Publishing, 2002, pp199-210

12. Dandy WE, Blackfan KD : An experimental and clinical study on internal hydrocephalus. JAMA $61:$ 2216-2217, 1913

13. Depreitere B, Dasi N, Rutka J, Dirks P, Drake J : Endoscopic biopsy for intraventricular tumors in children. J Neurosurg 106(5 Suppl) : 340346, 2007

14. Desai KI, Nadkarni TD, Muzumdar DP, Goel AH : Surgical management of colloid cyst of the third ventricle--a study of 105 cases. Surg Neurol 57 : 295-302; discussion 302-304, 2002

15. Dorward N, Alberti O, Velani B, Gerritsen FA, Harkness WF, Kitchen ND, et al. : Postimaging brain distortion: magnitude, correlates, and impact on neuronavigation. J Neurosurg 88 : 656-662, 1998

16. El-Ghandour NM : Endoscopic treatment of intraparenchymal arachnoid cysts in children. J Neurosurg Pediatr 14 : 501-507, 2014

17. El-Ghandour NM : Endoscopic treatment of suprasellar arachnoid cysts in children. J Neurosurg Pediatr 8 : 6-14, 2011

18. Fox JL, Al-Mefty 0 : Suprasellar arachnoid cysts: an extension of the membrane of Liliequist. Neurosurgery 7 : 615-618, 1980

19. Fukushima $T$ : Endoscopic biopsy of intraventricular tumors with the use of a ventriculofiberscope. Neurosurgery 2 : 110-113, 1978

20. Gaab MR, Schroeder HW : Neuroendoscopic approach to intraventricular lesions. Neurosurg Focus 6 : e5, 1999

21. Greenfield JP, Souweidane MM : Endoscopic management of intracranial cysts. Neurosurg Focus 19 : E7, 2005

22. Greenlee JD, Teo C, Ghahreman A, Kwok B : Purely endoscopic resection of colloid cysts. Neurosurgery 62(3 Suppl 1) : 51-55; discussion 5556, 2008

23. Husain $N$, Kumari M, Husain $M$ : Tumor irrigation fluid enhances diagnostic efficacy in endoscopic biopsies of intracranial space-occupying lesions. Acta Neurochir (Wien) 152 : 111-117, 2010

24. Husain M, Rastogi M, Jha DK, Husain N, Gupta RK : Endoscopic tranaqueductal removal of fourth ventricular neurocysticercosis with an angiographic catheter. Neurosurgery 60(4 Suppl 2) : 249-253; discussion 254, 2007

25. lacono RP, Labadie EL, Johnstone SJ, Bendt TK : Symptomatic arachnoid cyst at the clivus drained stereotactically through the vertex. Neurosurgery 27 : 130-133, 1990

26. lacoangeli M, di Somma LG, Di Rienzo A, Alvaro L, Nasi D, Scerrati M : Combined endoscopic transforaminal-transchoroidal approach for the treatment of third ventricle colloid cysts. J Neurosurg 120 : 14711476, 2014

27. Javedan SP, Manwaring K, Smith KA : Treatment of posterior third ventricular central neurocytoma with endoscopic biopsy, endoscopic third ventriculostomy and stereotactic radiosurgery. Minim Invasive Neurosurg 46 : 165-168, 2003

28. Levine NB, Miller MN, Crone KR : Endoscopic resection of colloid cysts: indications, technique, and results during a 13-year period. Minim Invasive Neurosurg $50: 313-317,2007$

29. Longatti P, Godano U, Gangemi M, Delitala A, Morace E, Genitori L, et al. : Cooperative study by the Italian neuroendoscopy group on the treatment of 61 colloid cysts. Childs Nerv Syst 22 : 1263-1267, 2006

30. Luther $\mathrm{N}$, Cohen A, Souweidane MM : Hemorrhagic sequelae from intracranial neuroendoscopic procedures for intraventricular tumors. Neurosurg Focus 19 : E9, 2005

31. Maher CO, Goumnerova $L:$ The effectiveness of ventriculocystocisternostomy for suprasellar arachnoid cysts. J Neurosurg Pediatr 7 : 6472, 2011

32. Manwaring JC, El Damaty A, Baldauf J, Schroeder HW : The smallchamber irrigation technique (SCIT): a simple maneuver for managing intra-operative hemorrhage during endoscopic intraventricular surgery. Neurosurgery $10: 375-379,2014$

33. Mathiesen $T$, Grane $P$, Lindquist $C$, von Holst $H$ : High recurrence rate following aspiration of colloid cysts in the third ventricle. J Neurosurg 78 : 748-752, 1993

34. Mishra S, Chandra PS, Suri A, Rajender K, Sharma BS, Mahapatra AK: Endoscopic management of third ventricular colloid cysts: eight years' institutional experience and description of a new technique. Neurol India 58 : 412-417, 2010

35. Oberbauer RW, Haase J, Pucher R : Arachnoid cysts in children: a European co-operative study. Childs Nerv Syst 8 : 281-286, 1992

36. Oertel JM, Baldauf J, Schroeder HW, Gaab MR : Endoscopic options in children: experience with 134 procedures. J Neurosurg Pediatr 3 : 81-89, 2009

37. Oppido PA, Fiorindi A, Benvenuti L, Cattani F, Cipri S, Gangemi M, et al. : Neuroendoscopic biopsy of ventricular tumors: a multicentric experience. Neurosurg Focus 30 : E2, 2011

38. Oretel JMK, Wagner W, Mondorf Y, Baldauf J, Schroeder HWS, Gaab MR : Endoscopic treatment of arachnoid cysts: a detailed account of surgical techniques and results. Neurosurgery 67 : 824-836, 2010

39. Ogiwara $H$, Morota $N$ : Flexible endoscopy for management of intraventricular brain tumors in patients with small ventricles. J Neurosurg Pediatr 14 : 490-494, 2014

40. Ogiwara H, Morota N, Joko M, Hirota K : Endoscopic fenestrations for suprasellar arachnoid cysts. J Neurosurg Pediatr 8 : 484-488, 2011

41. Rangel-Castilla L, Torres-Corzo J, Vecchia RR, Mohanty A, Nauta HJ : Coexistent intraventricular abnormalities in periventricular giant arach- 
noid cysts. J Neurosurg Pediatr 3 : 225-231, 2009

42. Rengachary SS, Kennedy JD : Intracranial arachnoid cysts and ependymal cysts in Wilkins RH, Rengachary SS (eds): Neurosurgery, ed 2. New York : McGraw-Hill, 1996, Vol 3, pp3709-3728

43. Rohde V, Reinges MH, Krombach GA, Gilsbach JM : The combined use of image-guided frameless stereotaxy and neuroendoscopy for the surgical management of occlusive hydrocephalus and intracranial cysts. $\mathbf{B r}$ J Neurosurg 12 : 531-538, 1998

44. Roth J, Constantini $\mathrm{S}$ : Combined rigid and flexible endoscopy for tumors in the posterior third ventricle. J Neurosurg 122 : 1341-1346, 2015

45. Santamarta D, Aguas J, Ferrer E : The natural history of arachnoid cysts: endoscopic and cine-mode MRI evidence of a slit-valve mechanism. Minim Invasive Neurosurg 38: 133-137, 1995

46. Schroeder HW, Oertel J, Gaab MR : Incidence of complications in neuroendoscopic surgery. Childs Nerv Syst $20: 878-883,2004$

47. Shapiro S, Rodgers R, Shah M, Fulkerson D, Campbell RL : Interhemispheric transcallosal subchoroidal fornix-sparing craniotomy for total resection of colloid cysts of the third ventricle. J Neurosurg 110 : 112115,2009

48. Sood S, Schulmann MU, Cakan N, Ham SD : Endoscopic fenestration and coagulation shrinkage of suprasellar arachnoid cysts. Technical note. J Neurosurg 102(1 Suppl) : 127-133, 2005

49. Souweidane MM: Endoscopic surgery for intraventricular brain tumors in patients without hydrocephalus. Neurosurgery 57(6 Suppl 3) : ONS312-ONS-318, 2005

50. Souweidane MM, Luther $N$ : Endoscopic resection of solid intraventricular brain tumors. J Neurosurg 105 : 271-278, 2006
51. Talamonti G, D'Aliberti G, Picano M, Debernardi A, Collice M : Intracranial cysts containing cerebrospinal fluid-like fluid: results of endoscopic neurosurgery in a series of 64 consecutive cases. Neurosurgery 68 : 788-803; discussion 803, 2011

52. Tamura Y, Kuroiwa T, Kajimoto Y, Miki Y, Miyatake Al, Tsuji M : Endoscopic identification and biopsy sampling of an intraventricular malignant glioma using a 5-aminolevulinic acid-induced protoporphyrin IX fluorescence imaging system. Technical note. J Neurosurg 106 : $507-$ 510, 2007

53. Torres-Corzo J, Rodriguez-della Vecchia R, Rangel-Castilla L : Bruns syndrome caused by intraventricular neurocysticercosis treated using flexible endoscopy. J Neurosurg 104 : 746-748, 2006

54. Wait SD, Gazzeri R, Wilson DA, Abla AA, Nakaji P, Teo C : Endoscopic colloid cyst resection in the absence of ventriculomegaly. Neurosurgery 73 (1 Suppl Operative) : ons39-ons46; ons46-ons47, 2013

55. Wang JC, Heier L, Souweidane MM : Advances in the endoscopic management of suprasellar arachnoid cysts in children. J Neurosurg 100(5 Suppl Pediatrics) : 418-426, 2004

56. Wei GZ, Li CJ, Meng JM, Ding MC : Cysticercosis of the central nervous system. A clinical study of 1,400 cases. Chin Med J (Engl) 101 : 493500, 1988

57. Zada G, Liu C, Apuzzo ML: "Through the looking glass": optical physics, issues, and the evolution of neuroendoscopy. World Neurosurg 77 : 92-102, 2012

58. Zamorano L, Chavantes C, Dujovny M, Malik G, Ausman J : Stereotactic endoscopic interventions in cystic and intraventricular brain lesions.

Acta Neurochir Suppl (Wien) 54 : 69-76, 1992 